\title{
Discriminatory Power of Women's Handball Game-Related Statistics at the Olympic Games (2004-2016)
}

\author{
by \\ Jose M. Saavedra ${ }^{1}$, Sveinn Porgeirsson ${ }^{1}$, Milan Chang1,2, Hafrún Kristjánsdóttir ${ }^{1}$, \\ Antonio García-Hermoso ${ }^{3,4}$
}

\begin{abstract}
Sports performance analysis has been a growing field of study in the last decade. However, the number of studies in handball is small. The aims of this present study were (i) to compare handball game-related statistics by the match outcome (winning and losing teams) and (ii) to identify characteristics that discriminated performance in elite women's handball. The game-related statistics of the 236 matches played in the last four Olympic Games (Athens, Greece, 2004; Beijing, China, 2008; London, United Kingdom, 2012; and Rio de Janeiro, Brazil, 2016) were analysed. Differences between match outcomes (winning or losing teams) were determined using the chi-squared statistic, also calculating the effect sizes of the differences. A discriminant analysis was then performed applying the sample-splitting method according to match outcomes. The results showed the differences between winning and losing teams were red cards and assists. Also, the discriminant analysis selected five variables (shots, goalkeeper-blocked shots, technical fouls, steals, and goalkeeper-blocked fast-break shots) that classified correctly $83 \%$ of matches. The selected variables included offensive and defensive predictors. Coaches and players can use these results as a reference against which to assess their performance and plan training.
\end{abstract}

Key words: performance analysis, notational analysis, discriminant analysis, match analysis, goalkeeper.

\section{Introduction}

Women's team-handball (handball) has been an Olympic sport since 1976. This has contributed to the great popularity of handball among the youth, with around 19 million players worldwide (International Handball Federation, 2014). Handball is a complex sport in which individual performance (physiological, technical, and psychological, among others) as well as tactical components are important (Wagner et al., 2014). In regard to its characteristics, it is an intermittent high intensity body contact team sport (Gorostiaga et al., 2005) where speed, agility, coordination, power, endurance, and strength are very important to be able to throw, pass, jump, hit, block, push, run, and dribble (Milanese et al., 2012). Handball is played in two periods of $30 \mathrm{~min}$ each where two teams of seven players (goalkeeper and six field players) try to achieve the maximum number of goals. Despite its popularity, mainly in Europe, handball research has been scarce. Only 373 articles with handball as a main subject had been published until 2012, but the sport has been covered more frequently from 2010 (Prieto et al., 2015b). The most frequently studied topics included: injuries $(26.5 \%)$, physical capacities and conditions

\footnotetext{
1 - Physical Activity, Physical Education, Sport and Health Research Centre (PAPESH), Sports Science Department, School of Science and Engineering, Reykjavik, Iceland.

2 - The Icelandic Gerontological Research Center, Reykjavik, Iceland.

3 - Laboratorio de Ciencias de la Actividad Física, el Deporte y la Salud, Facultad de Ciencias Médicas, Universidad de Santiago de Chile, Santiago de Chile, Chile.

4 - Facultad de Ciencias de la Educación, Universidad San Sebastian, Santiago de Chile, Chile.
} 
$(18.0 \%)$, physiological variable measurements $(12.9 \%)$, and performance and success variables (6.2\%) (Prieto et al., 2015b). Most of these articles were about men's handball, while there is a lack of research on women's handball (Prieto et al., 2015a).

Sports performance analysis has been a growing field of study in the last decade. Technological advances have allowed for a more detailed and time efficient analysis of athletes and team performance (O'Donoghue, 2010) including match analysis. This type of analysis has been done for women's teams in other sports, such as basketball (Gómez Ruano et al., 2007; Moreno et al., 2013), soccer (Pollard and Gomez, 2014; Soroka and Bergier, 2010), volleyball (GarcíaHermoso et al., 2013; Grgantov et al., 2006), and water polo (Escalante et al., 2012; Saavedra et al., 2016). However, in handball the number of studies is small. At the 2003 World Championship (preliminary round), 15 matches were analysed (regression analysis) to examine the relationship between backcourt attackers and the final goal differences. The predictor variables were goals from wing and pivot players (Gruić et al., 2005). Another study by the same authors (Ohnjec et al., 2008) analysed 120 matches in the same championship and found that the predictor variables of performance in each preliminary group (four groups with six teams in each) were different. Only wing shots missed variable was relevant in three out of four studied groups as a predictor variable. Subsequently, in the 2009 World Championship the efficiency (goals per shot) was analysed among all participating teams, and the fast-break efficiency among the four top teams (Spain, Norway, France, and Russia) (Calin, 2010). The study showed that $23 \%$ of the total goals were achieved in fast breaks, with this also being the most efficient shot. In the qualification round for the 2010 World Championship, the match results (three matches) depended on shots (goals and efficiency) and fast-break goals (Sucha and Pears, 2012). Another study of the World Championships (2007 and 2009) showed that world-class players used a higher number of movement variations (step patterns, changes in speed...) than national team players (Japan) (Yamada et al., 2011). Other studies have analysed the "league system" or Junior World Championships. One of these studies showed that home advantage in the Spanish League was greater for men than for women, and greater in the first division (top level) than in the second division (Pollard and Gómez, 2012). Another study used a more sophisticated approach (artificial neural networks - Junior World Championship in 2001) to analyse types of tactical team structures and to identify a number of such types representing play processes with similar tactical structures (Pfeiffer and Perl, 2006). The methodological approach was relevant for match analysis, but the results were inconclusive. Most of these studies have been of only one or two championships, each of which with a system of preliminary, quarter-final, semi-final, and final rounds. They have thus analysed just a limited number of matches. It was therefore important to study a greater number of championships and matches, to obtain a more solid picture of the trends in this topic.

Given this context, the objectives of the present study were: (i) to compare handball game-related statistics by the match outcome (winning and losing teams), and (ii) to identify characteristics that discriminated performance in elite women's handball.

\section{Methods}

\section{Participants}

We analysed the results and game-related statistics of 236 women's matches played in the last four Olympic Games (Athens, Greece, 2004; Beijing, China, 2008; London, United Kingdom, 2012; and Rio de Janeiro, Brazil, 2016).

\section{Procedures}

All the results were retrieved from the results books on the official website of the International Handball Federation (IHF) (http://www.ihf.info/IHFCompetitions/OlympicG ames/). The data were retrieved by a technician (see Acknowledgements), and entered manually into an Excel file. They were then subjected to a random check by one of the authors (JMS) in order to detect possible errors. Afterwards, the data were analysed statistically. No informed consent was necessary as the information used was in the public domain on the website. The analysis of public data taken from websites is habitual in the field of handball (Calin, 2010; Meletakos et al., 2011; Yamada et al., 2011; Pollard and Gomez, 2012). The IHF's technicians have 
been codifying matches for more than twenty years. Nevertheless, as a check of the reliability of their data, we calculated the inter-rater agreement for three matches as represented by Cohen's kappa by comparing that data with the data recorded by one of the present authors. In all cases, the value of kappa was greater than 0.89 .

In this study, the independent variable was the match outcome (winning and losing teams) and the dependent variables were the game-related statistics considered in Table 1 . These game-related statistics were already of general use among women's handball coaches and technicians, and were those that had been used in earlier studies (Meletakos et al., 2011).

\section{Statistical analysis}

Basic statistical descriptors (mean and standard deviation) were calculated by the match outcome (winning and losing teams). The significance of the descriptors distinguishing between winning and losing teams was determined by means of a chi-squared test, the recommended technique when the descriptors are discrete frequency response variables (Nevill et al., 1999, 2002). The effect sizes of the differences were calculated (Cohen, 1988). These values were interpreted in terms of size, following recommendations in the literature (Hopkins et al., 2009): $>0.1$ small, $>0.3$ moderate, $>0.5$ large, $>0.7$ very large, and $>0.9$ nearly perfect. Also a discriminant analysis was performed using the sample-splitting method according to the match outcome (winning and losing teams). The criterion used to determine whether or not a variable was discriminatory was Wilks's lambda, which measures the deviations within each group with respect to the total deviations. The samplesplitting method included initially the variable that best minimized the value of $l$, provided that the value of $\mathrm{F}$ was greater than a certain critical value ( $F=3.84$, "include"). From that point on, the method combined the variables pairwise. The new variable was selected if 1 was greater than the value of the input $F$. However, before introducing a variable, an attempt to eliminate some of those already selected was performed, as long as the increase in the minimized 1 was below a critical threshold ( $\mathrm{F}=2.71$, "remove"). We thus calculated 1 , the canonical correlation index (deviations of the between-group discriminant scores relative to the total deviations), and the percentage of correctly classified matches (winning and losing teams). A $p$-value $<0.05$ was considered to be statistically significant. The statistical analysis was performed with the software package SPSS version 15.0 (SPSS Inc., Chicago, IL, USA).

\section{Results}

Table 2 presents the basic descriptors of the variables by the match outcome (winning/losing teams). Only two variables (red cards and assists) were different between winning and losing teams.

Table 3 presents the results of the discriminant analysis (Wilks's lambda, the canonical correlation index, and the percentage of teams correctly classified) for the match outcome. The predictive models classified correctly $83 \%$ of matches using five variables: shots, goalkeeper-blocked shots, technical fouls, steals, and goalkeeper-blocked fast-break shots.

\section{Discussion}

Handball is a combination of complex performance capacities of mental and physical dimensions among individual players. Because of constantly repeated high-intensity actions throughout a handball match (e.g., jumps, sprints, changes of direction, duels, contacts), handball can be considered a very intense activity for all players (Karcher and Buchheit, 2014). Handball performance has been studied from several points of view. One of them, match analysis, has increased interest in examining the relationship between game-related statistics and the match outcome. This type of analysis is currently one of the popular approaches to identifying the most important factors for winning the game (Meletakos, 2011).

To the best of our knowledge, the present study has been the first to report the influence of game-related statistics on the outcome of women's handball matches $(n=236)$, followed by a discriminant analysis of those statistics to predict the winning/losing teams in the last four Olympic Games (2004 to 2016). 


\section{Table 1}

\section{Definitions of game-related statistics}

\begin{tabular}{|c|c|}
\hline Variable & Definition \\
\hline Shots & Percentage of converted shots relative to the number of shots made. \\
\hline $6 \mathrm{~m}$ shots & $\begin{array}{l}\text { Percentage of converted shots at } 6 \mathrm{~m} \text { relative to the number of shots made. The area } \\
\text { is from a zone outside the } 45^{\circ} \text { angle from the left and right. }\end{array}$ \\
\hline $7 \mathrm{~m}$ shots & Percentage of penalties $(7 \mathrm{~m})$ converted relative to the number of penalties taken. \\
\hline $9 \mathrm{~m}$ shots & $\begin{array}{l}\text { Percentage of converted shots at } 9 \text { m relative to the number of shots made. The area } \\
\text { from a backcourt player either (a) over or through the defence, and (b) after a } \\
\text { breakthrough but with another defence player in front. }\end{array}$ \\
\hline Wing shots & $\begin{array}{l}\text { Percentage of converted shots in the wing area relative to the number of shots made. } \\
\text { The area is from within an angle of } 45^{\circ} \text { left and right without a defence player in } \\
\text { front. }\end{array}$ \\
\hline $\begin{array}{l}\text { Fast-break } \\
\text { shots }\end{array}$ & $\begin{array}{l}\text { Percentage of shots converted in a fast-break situation - rapid switch from defence } \\
\text { to attack without defence organized - relative to the number of shots made in this } \\
\text { situation. }\end{array}$ \\
\hline $\begin{array}{l}\text { Breakthrough } \\
\text { shots }\end{array}$ & $\begin{array}{l}\text { Percentage of shots converted in a breakthrough situation - (a) from the backcourt } \\
\text { players after breakthrough in the } 9 \mathrm{~m} \text { zone without a defence player in front, (b) of } \\
\text { the pivot after 1:1 situation, (c) from the left or right back after breaking through 1:1 } \\
\text { situations - relative to the number of shots made in this situation. }\end{array}$ \\
\hline Yellow card & Yellow cards received by each player and/or coaching staff. \\
\hline Red card & Red cards received by each player and/or coaching staff. \\
\hline $\begin{array}{l}\text { 2-minutes } \\
\text { exclusions }\end{array}$ & 2-min suspension received by each player and/or coaching staff. \\
\hline Assists & $\begin{array}{l}\text { Number of passes from one offensive player to another leading directly to a goal } \\
\text { score. }\end{array}$ \\
\hline $\begin{array}{l}\text { Technical } \\
\text { fouls }\end{array}$ & $\begin{array}{l}\text { Number of turnovers made by the offensive team where the ball is awarded to the } \\
\text { defence due to offensive fouls. }\end{array}$ \\
\hline Steals & $\begin{array}{l}\text { Number of turnovers in favour of the defence due to actions of anticipation and } \\
\text { snatching the ball. }\end{array}$ \\
\hline G.B. shots & Percentage of shots stopped relative to the number of shots made by the attackers. \\
\hline G.B. $6 \mathrm{~m}$ shots & $\begin{array}{l}\text { Percentage of shots stopped at } 6 \mathrm{~m} \text { relative to the number of shots made by the } \\
\text { attackers. }\end{array}$ \\
\hline G.B. $7 \mathrm{~m}$ shots & $\begin{array}{l}\text { Percentage of penalties }(7 \mathrm{~m}) \text { stopped relative to the number of penalties taken by } \\
\text { the attackers. }\end{array}$ \\
\hline G.B. $9 \mathrm{~m}$ shots & $\begin{array}{l}\text { Percentage of shots stopped at } 9 \mathrm{~m} \text { relative to the number of shots made by the } \\
\text { attackers. }\end{array}$ \\
\hline G.B. wing shot & $\begin{array}{l}\text { Percentage of shots stopped in the wing area relative to the number of shots made } \\
\text { by the attackers. }\end{array}$ \\
\hline G.B. fast break & $\begin{array}{l}\text { Percentage of shots stopped in fast-break situations relative to the number of shots } \\
\text { made by the attackers. }\end{array}$ \\
\hline $\begin{array}{l}\text { G.B. } \\
\text { breakthroughs }\end{array}$ & $\begin{array}{l}\text { Percentage of shots stopped in breakthroughs situations relative to the number of } \\
\text { shots made by the attackers. }\end{array}$ \\
\hline
\end{tabular}


Table 2

Basic descriptors (mean and standard deviation), chi-squared statistic, p-value, and the effect sizes of the differences (Cohen's d) for each variable according to the match outcome

\begin{tabular}{|c|c|c|c|c|c|}
\hline & $\begin{array}{l}\text { Winners } \\
\mathrm{M} \pm \mathrm{SD}\end{array}$ & $\begin{array}{l}\text { Losers } \\
\mathrm{M} \pm \mathrm{SD}\end{array}$ & $\mathbf{X}^{2}$ & p & $E S$ \\
\hline Shots $(\%)^{\mathrm{a}}$ & $58.9 \pm 7.6$ & $49.3 \pm 7.9$ & 415.88 & 0.076 & 0.53 \\
\hline $6 \mathrm{~m}$ shots $(\%)^{\mathrm{a}}$ & $69.0 \pm 17.2$ & $64.4 \pm 20.6$ & 96.60 & 0.732 & 0.12 \\
\hline $7 \mathrm{~m}$ shots $(\%)^{\mathrm{a}}$ & $72.2 \pm 26.1$ & $71.5 \pm 27.5$ & 51.89 & 0.255 & 0.01 \\
\hline $9 \mathrm{~m}$ shots $(\%)^{\mathrm{a}}$ & $39.5 \pm 13.0$ & $29.9 \pm 11.6$ & 227.19 & 0.051 & 0.36 \\
\hline Wing shots $(\%)^{\mathrm{a}}$ & $55.9 \pm 21.2$ & $45.3 \pm 19.2$ & 101.31 & 0.096 & 0.25 \\
\hline Fast-break shots $(\%)^{a}$ & $75.0 \pm 21.7$ & $68.0 \pm 26.3$ & 70.31 & 0.772 & 0.14 \\
\hline Breakthrough shots $(\%)^{a}$ & $70.9 \pm 25.9$ & $64.5 \pm 30.9$ & 63.97 & 0.166 & 0.11 \\
\hline Yellow card (n) & $3.0 \pm 0.6$ & $3.0 \pm 0.7$ & 19.79 & 0.471 & 0.01 \\
\hline Red card (n) & $0.1 \pm 0.3$ & $0.6 \pm 0.2$ & 5.98 & 0.050 & -0.70 \\
\hline $2 \min (\mathrm{n})$ & $3.9 \pm 2.0$ & $3.8 \pm 2.0$ & 19.79 & 0.471 & 0.03 \\
\hline Exclusions (n) & $0.1 \pm 0.2$ & $0.1 \pm 0.1$ & 1.15 & 0.564 & 0.01 \\
\hline Assists (n) & $14.3 \pm 4.0$ & $10.9 \pm 3.9$ & 62.79 & 0.033 & 0.40 \\
\hline Technical fouls (n) & $14.52 \pm 4.7$ & $17.1 \pm 5.3$ & 64.15 & 0.120 & -0.25 \\
\hline Steals (n) & $5.5 \pm 3.2$ & $4.4 \pm 3.0$ & 35.69 & 0.299 & 0.18 \\
\hline Attacks (n) & $60.0 \pm 6.8$ & $59.9 \pm 6.9$ & 35.97 & 1.000 & 0.01 \\
\hline G.B. shots $(\%)^{b}$ & $37.5 \pm 8.7$ & $29.4 \pm 7.8$ & 323.70 & 0.557 & 0.44 \\
\hline G.B. $6 \mathrm{~m}$ shots $(\%)^{\mathrm{b}}$ & $28.6 \pm 20.3$ & $23.6 \pm 16.7$ & 60.14 & 0.933 & 0.13 \\
\hline G.B. $7 \mathrm{~m}$ shots $(\%)^{\mathrm{b}}$ & $20.5 \pm 24.2$ & $18.9 \pm 22.6$ & 33.55 & 0.586 & 0.03 \\
\hline G.B. $9 \mathrm{~m}$ shots $(\%)^{\mathrm{b}}$ & $54.6 \pm 17.3$ & $43.8 \pm 15.8$ & 180.77 & 0.085 & 0.31 \\
\hline G.B. wing shot $(\%)^{\mathrm{b}}$ & $43.1 \pm 23.1$ & $32.6 \pm 21.8$ & 62.95 & 0.712 & 0.23 \\
\hline G.B. fast break $(\%)^{\mathrm{b}}$ & $21.0 \pm 23.4$ & $19.3 \pm 20.6$ & 86.18 & 0.092 & 0.04 \\
\hline G.B. breakthroughs $(\%)^{\mathrm{b}}$ & $22.2 \pm 25.1$ & $21.7 \pm 23.0$ & 71.32 & 0.916 & 0.01 \\
\hline
\end{tabular}

a number of shots converted/number of shots; $b$ number of shots saved/number of shots; G.B. = goalkeeperblocked, ES $=$ effect sizes 


\begin{tabular}{|c|c|}
\hline \multicolumn{2}{|c|}{$\begin{array}{l}\text { Table } 3 \\
\text { Discriminant analysis models by the match outcome (winning and losing teams), } \\
\text { giving the percentage correctly classified, Wilks's lambda, canonical correlation index, } \\
\text { and variables included in the model by order of selection }\end{array}$} \\
\hline Percentage correctly classified & 83.0 \\
\hline Wilks's lambda & 0.514 \\
\hline Canonical correlation index & 0.697 \\
\hline Variables selected & $\begin{array}{l}\text { Shots, goalkeeper-blocked shots, technical fouls, steals, } \\
\text { goalkeeper-blocked fast-break shots }\end{array}$ \\
\hline
\end{tabular}

Previous studies analysed just one or two championships: World (Calin, 2010; Gruić et al., 2005; Ohnjec et al., 2008), European (Sucha and Pears, 2012; Yamada et al., 2011), World Junior (Pfeiffer and Perl, 2006), or league systems (Pollard and Gomez, 2012). This last study was an exception in that it analysed more than 10000 matches, yet it studied only home advantage in the Spanish League (Pollard and Gomez, 2012). The main findings of the current study indicated that in the last four Olympic Games (i) the variables differentiating between winners and losers were red cards and assists, and (ii) five variables (shots, goalkeeper-blocked shots, technical fouls, steals, and goalkeeper-blocked fast-break shots) predicted $83 \%$ of the match outcomes. In general, this study could be used by researchers to better understand the influence of game-related statistics on the final performance. Coaches could also use these game-related statistics in their training programs.

In regard to the differences by the match outcome (winning/losing teams), only two variables differentiated between winning and losing teams: red cards (winners $=0.1 \pm 0.3$, mean and standard deviation, losers $=0.6 \pm 0.2$, mean and standard deviation, $\mathrm{X} 2=5.98, \mathrm{p}=0.050, \mathrm{ES}=$ 0.70 ) and assists (winners $=14.3 \pm 4.0$, mean and standard deviation, losers $=10.9 \pm 3.9$, mean and standard deviation, $\mathrm{X} 2=62.79, \mathrm{p}=0.033, \mathrm{ES}=$ $0.40)$. To the best of our knowledge, previous studies did not include red cards in the gamerelated statistics they worked with. Red cards are a relevant sanction as they leave the team that commits the infringement in a situation of numerical inferiority. This sanction is mainly committed either because of poor technical mastery of the game's actions, or because of situations of superiority of the rival team which force a player to commit a serious infraction. Nonetheless, a high number of red cards is a consequence of situations of excessive aggressiveness, which can lead to injuries (Piry et al., 2011). As for assists, a previous study found a relationship between these and the number of converted goals (Gruić et al., 2005), indicating that winning teams cooperated more frequently than losing teams. Also, this could indicate that winning teams were more effective in shot selection and the players looked for other options to shoot. However, it should be noted that there seems to be a decreasing tendency in the average number of assists per game in winning teams. Thus, in a previous study conducted in the 2003 World Championship, the average number of assists per match was 19.4 (Ohnjec et al., 2008), 
whereas in the current study it was 14.3. It was also observed that no variables related to shots showed differences between winning teams and losers in contrast with previous studies where there was a relationship between the final goal differences and the converted goals in wing and pivot positions (Gruić et al., 2005).

The discriminatory power analysis showed that five variables (shots, goalkeeperblocked shots, technical fouls, steals, and goalkeeper-blocked fast-break shots) could correctly classify $83 \%$ of the teams (winning and losing). These results reflect the importance of creating offensive situations that allow offensive actions to be finalized with effective shots. Previous studies have shown that shots (converted and efficiency, i.e., number of shots converted/number of shots) constituted a predictive variable in the 2010 European Women's Handball Championship qualification round (Sucha and Pears, 2012). Other studies that used the same analysis (multiple regression) found that converted shots in pivot and wing positions were predictors of the final goal difference (Gruić et al., 2005). One of the clear trends in the analysis of game-related statistics is that most of the performance indicators included in the analysis of match outcomes have been attack related indicators. In the present study, two goalkeeper variables were selected by the model (goalkeeperblocked shots and goalkeeper-blocked fast-break shots), emphasizing that opposing shots have to be stopped by the goalkeeper's action itself, by selecting defensive systems that do not permit the opponent to get into comfortable shooting situations, or by a combination of the two. In addition, the results showed the importance of the goalkeeper's role in handball teams, especially in fast-break situations where a block could have positive psychological effects. It should be borne in mind that fast-break shots are the most used shots in women's handball matches (23\%) (Calin et al., 2010). With regard to technical fouls, it is necessary to achieve the sufficient offensive intensity to unbalance the defence without committing a technical foul. While the results suggest that the winning teams have a better control of the technical rules, they do not seem to be conclusive. In previous studies that used multiple regression analysis to examine the final goal differences in the four preliminary groups of the World Handball Championship (2003), it was found that technical fouls were a predictor variable in only two of the groups (Ohnjec et al., 2008). Finally, another variable selected was steals. They are the result of appropriate defensive strategies that cause the attacking team to lose possession, thus not only preventing the offensive action ending in a shot, but also giving the potential for a fast break. In this way, high performance efficiency among players usually leads to adaptive defence tactics aimed at preventing the ball from reaching the goal.

This study has some limitations. First, the discriminant analysis used post hoc prediction. In interpreting the results, it needs to be borne in mind that this type of prediction usually gives higher values for the classification than a priori predictions. In the same sense, these results could differ if the championships used were the "Regular League". Second, only top-level championships were analysed (Olympic Games), thus these findings should be carefully interpreted in the context of national and local handball game statistics. Third, this study has a static perspective. The game-related statistics were "the final result" without attention paid to what happened at each moment of the match (dynamic perspective) (Prieto et al., 2015). In this regard, certain game situations could have influenced the play that followed. For example, a goalkeeper save could lead to a favourable counterattack situation.

In summary, this study compared handball game-related statistics by the match outcome (winning and losing teams) and identified characteristics that discriminated performance in elite women's handball. The main conclusions were: (i) the variables differentiating between winning and losing teams were red cards and assists, and (ii) the variables discriminating between the teams were shots, goalkeeperblocked shots, technical fouls, steals, and goalkeeper-blocked fast-break shots. The selected variables included offensive and defensive predictors. The present results allow coaches and researchers to better understand the relative significance of handball game-related statistics in an international context. In addition, coaches and players can use these results as a reference against which to assess their performance and plan training. 


\section{Acknowledgements}

The authors wish to thank Brian Daniel Marshall MSc for revising the English text, also Kolbrún Helga Hansen for introducing the data in computer.

\section{References}

Calin R. The analysis of the efficiency of using fastbreaks in female handball during the World Championship in China 2009. Sci Mov Health, 2010; 2: 594-599

Cohen J. Statistical power analysis for the behavioral sciences. Routledge Academic; 1988

Escalante Y, Saavedra JM, Tella V, Mansilla M, García-Hermoso A, Dominguez AM. Water polo gamerelated statistics in Women's International Championships: Differences and discriminatory power. $J$ Sports Sci Med, 2012; 11: 475-482

García-Hermoso A, Dávila-Romero C, Saavedra JM. Discriminatory power of game-related statistics in 14-15 year age group male volleyball, according to set. Percept Mot Skills, 2013; 116: 132-143

Gómez Ruano MA, Lorenzo Calvo A, Ortega Toro E, Olmedilla Zafra A. Differences of the female performance indicators between winners and losers in function of home and away teams [Spanish]. Rev Psicol Deporte, 2007; 16: 41-54

Gorostiaga EM. Granados C, Ibañez J, Izquierdo M. Differences in physical fitness and throwing velocity between elite and amateur male handball players. Int J Sports Med, 2005; 26: 225-232.

Grgantov Z, Katic R, Jankovc V. Morphological characteristics, technical and situation efficacy of young female volleyball players. Coll Antropol, 2006; 30: 87-96

Gruić I, Vuleta D, Milanović D, Ohnjec K. Influence of performance parameters of backcourt attackers on final outcomes of matches of the 2003 World Handball Championships for Women in Croatia. In Milanovic D, Prot F. (Eds.). Proceedings $4^{\text {th }}$ International Scientific Conference on Kinesiology. Zagreb (Croatia): University of Zagreb, 474-477; 2005

Hopkins WG, Marshall SW, Batterham AM, Hanin J. Progressive statistics for studies in sports medicine and exercise science. Med Sci Sports Exerc, 2009; 41: 3-13

International Handball Federation. (2013). Handball. History and stories. Retrieved 30th July 2015, from http://techcrunch.comhttp://ihf.info/upload/Book/issue0001/index.html

Karcher C, Buchheit M. On-Court Demands of Elite Handball, with Special Reference to Playing Positions. Sports Med, 2014; 44: 797-814

Meletakos P, Vagenas G, Bayios I. A multivariate assessment of offensive performance indicators in Men's Handball: Trends and differences in the World Championships. Int J Perform Anal Sport, 2011; 11: 284294

Milanese C, Piscitelli F, Lampis C, Zancanaro C. Effect of a competitive season on anthropometry and threecompartment body composition in female handball players. Biol Sport, 2012; 29: 199-204

Moreno E, Gómez MA, Lago C, Sampaio J. Effects of starting quarter score, game location, and quality of opposition in quarter score in elite women's basketball. Kinesiol, 2013; 45: 48-54

Nevill A, Balmer N, Williams M. Crowd influence on decisions in association football. Lancet, 1999: 353: 1416

Nevill AM, Atkinson G, Hughes M, Cooper SM. Statistical methods for analysing discrete and categorical data recorded in performance analysis. J Sports Sci, 2002, 20: 829-844

O'Donoghue P. Research methods for sports performance analysis. London: Routledge; 2010

Ohnjec K, Vuleta D, Milanović D, Gruić I. Performance indicators of teams at the 2003 World Handball Championship for women in Croatia. Kinesiol, 2008; 40: 69-79

Pfeiffer M, Perl J. Analysis of tactical structures in team handball by means of artificial neural networks. Int J Comput Sci Sport, 2006; 5: 4-14

Piry H, Alizade MH, Nasiri KH, Rahimi M. Injury rates in Iranian handball players. World Appl Sci J, 2011; 14: $1670-1677$ 
Pollard R, Gómez MA. Re-assessment of home advantage in Spanish handball: comment on Gutierrez, et al. (2012). Percept Mot Skills, 2012; 115: 937-943

Pollard R, Gómez MA. Comparison of home advantage in men's and women's football leagues in Europe. Eur J Sport Sci, 2014; 14: S77-S83

Prieto J, Gómez MA, Sampaio J. From a static to a dynamic perspective in handball match analysis: a systematic review. Open Sports Sci J, 2015a; 8: 25-34

Prieto J, Gómez MA, Sampaio J. A bibliometric review of the scientific production in handball. Cuadernos Psicol Deporte, 2015b; 15: 145-154

Saavedra JM, Escalante Y, Mansilla M, Tella V, Madera J, García-Hermoso A. Water polo game-related statistics in Women's International Championships as a function of final score differences. Int J Perform Anal Sport, 2016; 16: 276-289

Soroka A, Bergier J. Actions with the ball that determine the effectiveness of play in women's football. J Hum Kinet, 2010; 26: 97-104

Sucha MS, Pears DC. Notational analysis of three matches from the Women's Team Handball European 2010 Qualification Round. In Peters DM, O'Donoghue. PG. E-Book Abstract World Congress Performance Analysis Sport IX. Worcester (UK): University of Worcester, 126; 2012

Wagner H, Finkenzeller T, Würth S, von Duvillard SP. Individual and team performance in Team-Handball: A Review. J Sports Sci Med, 2012; 13: 808-816

Yamada E, Aida H, Nakagawa A. Notational analysis of shooting play in the middle area by world-class player and Japanese Elite players in woman's handball. Int J Sports Health, 2011; 9: 15-25

\section{Corresponding author:}

\section{Jose M. Saavedra}

Physical Activity, Physical Education, Health and Sport Research Centre (PAPESH). School of Science and Engineering. Reykjavik University. Menntavegur 1, Nauthólsvík, 101 Reykjavík, Iceland.

Phone: +354 5996200

Fax + 3545996201

E-mail: saavedra@ru.is 